\title{
Effects of pasteurization and different concentrations of xanthan gum on honey beverage
}

\author{
${ }^{1,2} *$ Norhayati, H., ${ }^{2}$ Izzreen, I. and ${ }^{1}$ Tan Hooi, P. \\ ${ }^{1}$ Department of Food Technology, Faculty of Food Science and Technology, Universiti Putra Malaysia, \\ 43400 Serdang, Selangor, Malaysia \\ ${ }^{2}$ Halal Products Research Institute, Putra Infoport, 43400 UPM Serdang, Selangor, Malaysia
}

Article history:

Received: 21 September 2018

Received in revised form: 4

December 2018

Accepted: 6 December 2018

Available Online: 11

December 2018

Keywords:

Pasteurization,

Honey beverages,

Xanthan gum,

Shelf life,

Physiochemical properties

DOI:

https://doi.org/10.26656/fr.2017.3(4).142

\begin{abstract}
Development of ready to drink (RTD) beverage containing honey as a natural ingredient to replace sugary (high calorie) beverage using pasteurization is a new emerging market. However, the stability of the beverage may be affected due to sedimentation in the solution thus the addition of xanthan gum to improve the stability was proposed. Therefore, the objective of this study was to evaluate the effects of pasteurization and different concentrations of xanthan gum $(0.05 \%$ and $0.1 \%)$ on the shelf life and physicochemical properties of honey beverages during storage at $25 \pm 2{ }^{\circ} \mathrm{C}$. The honey beverages were analyzed for total soluble solids (TSS), $\mathrm{pH}$, rheological behavior, total phenolic content (TPC) and total plate count after processing at a specified time interval until the samples were deteriorated. The beverage containing $0.1 \%$ of xanthan gum shows significantly $(\mathrm{p}<0.05)$ higher stability in terms of TSS and total plate count than honey beverages containing $0.05 \%$ xanthan gum. Both pasteurized $0.05 \%$ and $0.1 \%$ xanthan gum enriched honey beverages samples remain acceptable in terms of TSS, pH, TPC and total plate count during 10 weeks of storage. On the contrary, all unpasteurized honey beverages were deteriorated after the first week of storage. Thus, pasteurization and addition of xanthan gum of honey beverages are recommended for longer shelf life at room temperature.
\end{abstract}

\section{Introduction}

"Codex Alimentarius (2013) states that honey is the natural sweet substance produced by honeybees from the nectar of any plants, which the bees collect and transform it by combining with specific substances from bee itself and makes honey edible". In the beverage industry, honey provides unique advantages and usage consideration that ultimately assist in the development of a highly desirable end product. Honey is used as a sweetener in plenty of food products especially beverages due to its high level of fructose and glucose (Doner, 2006). Besides the sweetener property, honey also acts as a good antioxidant provider, used as a prebiotic, raw material for fermentation, clarifying agent, and flavor enhancer (Codex Alimentarius, 2013).

Nowadays, carbonated soft drinks (CSD) accounts for more than a quarter of all drinks consumed globally (Huber, 2016). The increased prevalence of overweight, obesity and chronic disease is partly attributable to an increase in unhealthy dietary behaviors (Drewnowski et $a l .$, 2007). The US Food and Drug Administration (FDA) states diseases link to carbonated drink consumption are obesity, type 2-diabetes and tooth decay not just in adults but also in children. Following this trend, there is an increasing demand for healthy and natural food products as today's consumers are seeking healthier food and drinks (Brian, 2015).

Today, ready to drink (RTD) honey beverage is rarely available in the market. According to a theory of sedimentation and centrifugation, sedimentation of honey occurs due to pollen grain that migrates to the bottom of the solution under influence of gravity (Peter and Aylor, 2009). Thus, the addition of xanthan gum is required to improve the appearance and color of RTD honey. However, permitted level of preservative to be added to food or drinks should strictly follow the Food Regulation to ensure the safety of the consumer. It is also important to know the rheology behaviors of honey beverages and how the viscosity changes with the processing condition and concentration of xanthan gum (Alvarez et al., 2006). Castro et al. (2009) stated that xanthan gum has acid, heat and enzyme stability which ensure no loss in viscosity over the shelf life of the 
xanthan gum enriched product thus making it an ideal stabilizer for sauces, dressings and beverages. However, none has studied on the application of xanthan gum in honey beverages since there is no study related to the production of RTD honey beverages yet.

Thermal pasteurization is the process most widely used in the food industry to ensure food safety. The processing temperature of honey beverage is critical because high temperature destroys heat sensitive nutrients like the antioxidant and L-ascorbic acid (Codex Alimentarius, 2013). The longer the storage time and processing temperature, the L-ascorbic acid declines (Tome et al., 2008). However, nutrient preserves better at the low processing temperature, but it allows biochemical and biological reaction that deteriorate the quality and shelf life of honey beverages. Thus, total plate count is important to determine the number of microorganism in food and to determine the food safety.

Development of RTD honey beverage could be a new emerging market for the beverages industry. It is a good alternative to replace unhealthy calorically sweetened beverages with honey due to its natural sweetener characteristics. Besides, it requires zero preparation time for consumers. Although many have studied the change of physicochemical properties and antioxidant properties of pasteurized honey, however, limited information is available on the production of honey as a beverage and its processing conditions. Therefore, the objective of this study was to evaluate the effects of pasteurization and different concentrations of xanthan gum $(0.05 \%$ and $0.1 \%)$ on the shelf life, physicochemical and rheology properties of honey beverages during storage at $25 \pm 2{ }^{\circ} \mathrm{C}$.

\section{Materials and methods}

\subsection{Sample preparation}

Polleney commercial honey (Pure honey) is produced under strict quality control by the trademark owner, Huamao Agencies Sdn Bhd and purchased from IOI city mall, Putrajaya Malaysia. Xanthan gum from Xanthomonas campestris was purchased from Aldrich, Germany. Glass bottles with a screw cap as a container of the sample were sterilized and dried at $55^{\circ} \mathrm{C}$ in an oven (Mammert, Germany) under forced-air ventilation.

The honey was added into reverse osmosis water at a ratio of $3: 10$ as a stock solution. On the other hand, xanthan gum was dissolved into the reverse osmosis water in $5 \mathrm{~L}$ plastic jar at room temperature using a homogenizer (Model L2R, Siverson, England) for $2 \mathrm{hrs}$ at a percentage of $0 \%$ (as a control), $0.05 \%$ and $0.1 \%$. Food categories listed under US FDA (2002) has recommended a level of xanthan gum in beverages bases and non-alcohol drinks shall be between $0.05 \%$ and $0.1 \%$. The prepared xanthan gum was then added into the honey solution before pasteurization and mixed well using a homogenizer. The unpasteurized honey beverages were then poured into sterilized glass bottles and labeled as unpasteurized $0 \%, 0.05 \%$ and $0.1 \%$ of xanthan gum respectively.

Lab scale pasteurization was conducted at $72^{\circ} \mathrm{C}$ for $15 \mathrm{~s}$ which follows similar practice for all types of juices (Gabriel and Nakano, 2009) to reduce the growth of vegetative pathogens where all the sterilized small bottles were hot filled with the beverages after being pasteurized and labeled as pasteurized $0 \%, 0.05 \%$ and $0.1 \%$ of xanthan gum respectively.

\subsection{Experimental design}

Unpasteurized and pasteurized honey beverages containing a different concentration of xanthan gum were stored at room temperature $\left(25 \pm 2^{\circ} \mathrm{C}\right)$ for 10 weeks after processing. Samples were evaluated and observed for 10 weeks at different time interval depending on the different analysis conducted. For instance, total plate count was analyzed at only week $0,2^{\text {nd }}, 4^{\text {th }}, 6^{\text {th }}, 8^{\text {th }}, 10^{\text {th }}$ week, while the sample was analyzed at $0,1^{\text {st }}, 2^{\text {nd }}, 6^{\text {th }}$ and $10^{\text {th }}$ week for antioxidant analysis. The stored beverages were analyzed until their quality deteriorated, for example; the presence of microorganism as the sign of spoilage (Oliveira et al., 2012).

\subsection{Physicochemical analysis}

\subsubsection{Total soluble solids (TSS) and $p H$}

Triplicate samples were analyzed once a week from week 0 to week 4 . Because of no significant changes occurred after week 4 , the samples were analyzed once in two weeks interval, which was from week 6 to week 10. The $\mathrm{pH}$ measurements were determined using digital $\mathrm{pH}$ meter (Jenway 3505, UK) at room temperature $25 \pm 2^{\circ}$ $\mathrm{C}$ whereas total soluble solids were determined using digital refractometer (Reed, USA) with 0 to $32^{\circ}$ Brix. Total soluble solid value of the sample was expressed as ${ }^{\circ}$ Brix.

\subsubsection{Rheological measurement}

The rheological measurements of honey beverages were carried out using rotational rheometer (RheolabQC, Germany) to determine the viscosity and flow properties of the samples. Samples were gently shaken before pouring into drag cup in the rheometer, locked firmly before starting to measure and record data. All rheological measurements were carried out in triplicate at room temperature $25 \pm 2^{\circ} \mathrm{C}$. 


\subsubsection{Determination of total phenolic content (TPC)}

The concentration of total phenolic was measured using Folin-Ciocalteu phenol reagent (Habib et al., 2014). The results were expressed as milligram of gallic acid equivalents (mg GAE) per $100 \mathrm{~g}$ of honey beverage.

\subsection{Total plate count}

For the microbiological analysis, total plate count was determined using the plate count agar (PCA) (Merck, Germany) and Dichloran Rose Bengal Chloramphenicol (DRBC) agar (Condalab, Spain). The growth of viable bacteria was observed and colonies were counted using colony counter (Chia et al., 2012).

\subsection{Statistical analysis}

Data represent the mean of triplicate samples from each analysis. One Way analysis of variance (ANOVA) at $95 \%$ confidence levels was conducted using MINITAB 17.

\section{Results and discussion}

\subsection{TSS of honey beverage}

The total soluble solid (TSS) is the sum of the solids which are soluble in solution, and these soluble solids are primarily sugars such as sucrose, fructose and glucose (Chia et al., 2012). Thus, TSS shows a high positive correlation with sugars content and generally accepted as an important quality trait of honey and their product. Table 1 shows the effects of pasteurization and concentration of xanthan gum on the TSS ( ${ }^{\circ}$ Brix) of honey beverages in a period of ten weeks. The ${ }^{\circ}$ Brix of thermally pasteurized xanthan gum enriched honey beverages were significantly higher $(p<0.05)$ than the unpasteurized honey beverages. These results agree with those reported by Tandon et al. (2003) that the soluble solid of pasteurized orange juice was significantly increased.

From Table 1, TSS of unpasteurized honey beverages containing $0 \%$ (control), $0.05 \%$ and $0.1 \%$ of xanthan gum started to decrease significantly $(p<0.05)$ during the first week of storage and continued to decrease significantly until spoilt at 4 th week. The change in TSS was suspected to be due to the sugar fermentation process of microorganism present in the beverages which result in deterioration (Rivas et al., 2006). Microorganisms such as mold, yeasts and fungus that cause fermentation can break down glucose present in sugary beverages through the biochemical pathway and therefore decrease its Brix (Rosen and Gothard, 2010; Xiang et al., 2014). The fermentation process in unpasteurized honey beverages might take place during the first week as there were noticeable fermented smell and gas bubbles.

In contrast, TSS of pasteurized honey beverages containing $0.1 \%$ of xanthan gum show significant decreased $(p<0.05)$ during first four weeks of storage and decreased insignificantly $(\mathrm{p}>0.05)$ from week 4 to week 10. This result was similar as reported by Bull et al. (2004) that the Brix of thermally processed Valencia and Navel orange juice did not change significantly $(p>0.05)$ during storage at $4{ }^{\circ} \mathrm{C}$ and $10^{\circ} \mathrm{C}$, thus indicated that the biological stability of the samples throughout the storage period.

On the other hand, both $0.05 \%$ and $0.1 \%$ xanthan gum enriched honey beverages show significantly $(p<0.05)$ higher TSS than $0 \%$ (control) in both unpasteurized and pasteurized honey beverages during storage duration from week 1 to week 10 . This result is similar as reported by Rungnaphar et al. (2011) that the TSS of blueberry syrup containing $0.1 \%$ to $0.3 \%$ of xanthan gum showed no significant $(p>0.05)$ different over 16 weeks of storage. In other words, xanthan gum slows down the fermentation process that might occur in beverages thus prevents deterioration of beverages (Rivas et al., 2006).

\section{$3.2 \mathrm{pH}$ of honey beverages}

Sanchez-Moreno et al. (2006) stated that $\mathrm{pH}$ is one of the important quality characteristics that describe the stability of the bioactive compound of sugary beverages. Microbial activity in a food product results in food molding, fermenting and change in acidity often is the most frequent reason for the deterioration of food product. Table 2 shows the effect of pasteurization and concentration of xanthan gum on the $\mathrm{pH}$ of honey beverages during 10 weeks of storage. In week 0 , the $\mathrm{pH}$ of pasteurized honey juices was significantly lower $(\mathrm{p}<0.05)$ than unpasteurized honey juice. Similarly, as reported by Chaikham and Apichartsrangkoon (2012) that $\mathrm{pH}$ of longan and pennywort juices pasteurized at $90^{\circ} \mathrm{C}$ for 2 mins were significantly lower than fresh juices. Queiroz et al. (2010) also stated that this phenomenon might be due to the thermal acceleration of hydrogen ion concentration resulted from sucrose hydrolysis and decomposition.

However, all the samples show decreased in $\mathrm{pH}$ from week 0 to week 10 with $\mathrm{pH}$ of unpasteurized honey juices decreased at a faster rate than pasteurized beverages. This might be due to the pasteurization process which could inhibit the growth of spoilage microorganisms in liquid food (Silva and Gibbs, 2004). Thus, absent of microbial metabolites that result in organic acids (acetic acid and lactic acid) production and 
Table 1. Total soluble solid ( ${ }^{\circ}$ Brix) of unpasteurized and pasteurized honey beverages during storage at $25 \pm 2^{\circ} \mathrm{C}$.

\begin{tabular}{ccccccc}
\hline \multirow{2}{*}{$\begin{array}{c}\text { Shelf } \\
\text { life }\end{array}$ (week) } & \multicolumn{5}{c}{ Total Soluble Solid $\left({ }^{\circ}\right.$ Brix $)$} \\
\cline { 2 - 7 } & \multicolumn{5}{c}{ Unpasteurized } \\
\cline { 2 - 6 } & 0 & 0.05 & 0.1 & 0 & 0.05 & 0.1 \\
\hline 0 & $30.0 \pm 0.2^{\mathrm{Aa}}$ & $29.9 \pm 0.2^{\mathrm{Aa}}$ & $29.9 \pm 0.1^{\mathrm{Aa}}$ & $30.2 \pm 0.1^{\mathrm{Aa}}$ & $30.4 \pm 0.1^{\mathrm{Aa}}$ & $30.6 \pm 0.1^{\mathrm{Aa}}$ \\
1 & $27.2 \pm 0.1^{\mathrm{Db}}$ & $28.1 \pm 0.1^{\mathrm{Cb}}$ & $28.6 \pm 0.1^{\mathrm{Bb}}$ & $26.0 \pm 0.2^{\mathrm{Eg}}$ & $28.6 \pm 0.1^{\mathrm{Be}}$ & $30.3 \pm 0.1^{\mathrm{Ab}}$ \\
2 & $27.2 \pm 0.2^{\mathrm{Db}}$ & $27.2 \pm 0.2^{\mathrm{Dc}}$ & $27.2 \pm 0.3^{\mathrm{Dc}}$ & $27.6 \pm 0.2^{\mathrm{Ce}}$ & $28.3 \pm 0.1^{\mathrm{Bf}}$ & $29.9 \pm 0.1^{\mathrm{Ac}}$ \\
3 & - & $26.7 \pm 0.1^{\mathrm{Dd}}$ & $26.5 \pm 0.1^{\mathrm{Ed}}$ & $27.2^{\mathrm{Ca}} \pm 0.1^{\mathrm{Cf}}$ & $29.4 \pm 0.1^{\mathrm{Bb}}$ & $29.8 \pm 0.1^{\mathrm{Ac}}$ \\
4 & - & $26.6 \pm 0.1^{\mathrm{Cd}}$ & $26.1 \pm 0.1^{\mathrm{De}}$ & $27.7 \pm 0.1^{\mathrm{Be}}$ & $29.3 \pm 0.0^{\mathrm{Ab}}$ & $29.4 \pm 0.1^{\mathrm{Ad}}$ \\
6 & - & - & - & $28.8 \pm 0.1^{\mathrm{Bc}}$ & $29.1 \pm 0.1^{\mathrm{Ac}}$ & $28.8 \pm 0.0^{\mathrm{Bf}}$ \\
8 & - & - & - & $29.0 \pm 0.1^{\mathrm{Ab}}$ & $29.1 \pm 0.1^{\mathrm{ABc}}$ & $29.2 \pm 0.1^{\mathrm{Ae}}$ \\
10 & - & - & - & $28.1 \pm 0.2^{\mathrm{Cd}}$ & $28.8 \pm 0.1^{\mathrm{Bd}}$ & $29.1 \pm 0.1^{\mathrm{Ae}}$ \\
\hline
\end{tabular}

Values are expressed as mean $\pm \mathrm{sd}$, and symbol - refers to deteriorated samples. Means with different capital letters within the row are significantly different $(\mathrm{p}<0.05)$. Means with different superscript low case letters within the column are significantly different $(\mathrm{p}<0.05)$.

Table 2. $\mathrm{pH}$ of unpasteurized and pasteurized honey beverages during storage at $25 \pm 2^{\circ} \mathrm{C}$.

\begin{tabular}{ccccccc}
\hline \multirow{2}{*}{$\begin{array}{c}\text { Shelf } \\
\text { life }\end{array}$} & \multicolumn{5}{c}{$\mathrm{pH}$} \\
\cline { 2 - 6 } (week) & \multicolumn{5}{c}{ Unpasteurized } \\
\cline { 2 - 7 } & 0 & 0.05 & 0.1 & 0 & 0.05 & 0.1 \\
\hline 0 & $4.51 \pm 0.05^{\mathrm{Aa}}$ & $4.46 \pm 0.04^{\mathrm{Aa}}$ & $4.48 \pm 0.04^{\mathrm{aa}}$ & $4.43 \pm 0.01^{\mathrm{ABa}}$ & $4.42 \pm 0.01^{\mathrm{ABa}}$ & $4.41 \pm 0.03^{\mathrm{Ba}}$ \\
1 & $4.30 \pm 0.01^{\mathrm{Db}}$ & $4.50 \pm 0.02^{\mathrm{Aa}}$ & $4.42 \pm 0.02^{\mathrm{Cb}}$ & $4.46 \pm 0.03^{\mathrm{Ba}}$ & $4.42 \pm 0.01^{\mathrm{Ca}}$ & $4.37 \pm 0.07^{\mathrm{Dab}}$ \\
2 & $3.11 \pm 0.01^{\mathrm{Dc}}$ & $3.35 \pm 0.06^{\mathrm{Cd}}$ & $3.32 \pm 0.02^{\mathrm{Cc}}$ & $4.00 \pm 0.02^{\mathrm{Bc}}$ & $4.31 \pm 0.02^{\mathrm{Abc}}$ & $4.30 \pm 0.01^{\mathrm{Ab}}$ \\
3 & - & $3.46 \pm 0.02^{\mathrm{Dc}}$ & $3.30 \pm 0.01^{\mathrm{Ec}}$ & $4.17 \pm 0.02^{\mathrm{Bb}}$ & $4.34 \pm 0.03^{\mathrm{Ab}}$ & $4.10 \pm 0.04^{\mathrm{Ce}}$ \\
4 & - & $3.72 \pm 0.02^{\mathrm{Db}}$ & $3.25 \pm 0.02^{\mathrm{Ed}}$ & $4.00 \pm 0.02^{\mathrm{Cc}}$ & $4.32 \pm 0.02^{\mathrm{Ab}}$ & $4.20 \pm 0.02^{\mathrm{Bc}}$ \\
6 & - & - & - & $3.94 \pm 0.04^{\mathrm{Cd}}$ & $4.28 \pm 0.01^{\mathrm{Ac}}$ & $4.16 \pm 0.03^{\mathrm{Bd}}$ \\
8 & - & - & - & $3.47 \pm 0.04^{\mathrm{Ce}}$ & $4.28 \pm 0.03^{\mathrm{Ac}}$ & $4.16 \pm 0.02^{\mathrm{Bd}}$ \\
10 & - & - & - & $3.27 \pm 0.01^{\mathrm{Cf}}$ & $4.24 \pm 0.02^{\mathrm{Ad}}$ & $4.11 \pm 0.03^{\mathrm{Be}}$ \\
\hline
\end{tabular}

Values are expressed as mean $\pm \mathrm{sd}$, and symbol - refers to deteriorated samples. Means with different capital letters within the row are significantly different $(\mathrm{p}<0.05)$. Means with different superscript lower case letters within the column are significantly different $(\mathrm{p}<0.05)$.

Table 3. Rheological parameters of unpasteurized and pasteurized honey beverages during storage at $25 \pm 2^{\circ} \mathrm{C}$.

\begin{tabular}{cccc}
\hline Type of sample & Xanthan gum concentration (\%) & Shear viscosity, $\eta$ & Shear stress, $\tau(\mathrm{Pa})$ \\
\hline \multirow{3}{*}{ Unpasteurized } & 0.00 & $4.3 \pm 0.0^{\mathrm{e}}$ & $6.67 \pm 0.56^{\mathrm{e}}$ \\
& 0.05 & $8.0 \pm 0.2^{\mathrm{c}}$ & $12.40 \pm 0.12^{\mathrm{c}}$ \\
& 0.10 & $12.0 \pm 0.3^{\mathrm{a}}$ & $18.60 \pm 0.43^{\mathrm{a}}$ \\
Pasteurized & 0.00 & $4.7 \pm 0.0^{\mathrm{d}}$ & $7.30 \pm 0.28^{\mathrm{d}}$ \\
& 0.05 & $9.1 \pm 0.5^{\mathrm{b}}$ & $14.11 \pm 0.26^{\mathrm{b}}$ \\
& 0.10 & $12.2 \pm 0.0^{\mathrm{a}}$ & $18.92 \pm 0.09^{\mathrm{a}}$ \\
\hline
\end{tabular}

Table 4. Total phenolic compounds of unpasteurized and pasteurized honey beverages during storage at $25 \pm 2^{\circ} \mathrm{C}$.

\begin{tabular}{ccccccc}
\hline & \multicolumn{5}{c}{ Total phenolic compounds (mg GAE/100g) } \\
\cline { 2 - 7 } Shelf life & \multicolumn{5}{c}{ Pasteurized } \\
\cline { 2 - 7 } (week) & \multicolumn{5}{c}{ Unpasteurized } \\
\cline { 2 - 7 } & 0 & 0.05 & 0.1 & 0 & 0.05 & 0.1 \\
\cline { 2 - 7 } & $188.11 \pm 4.06^{\mathrm{Aa}}$ & $187.64 \pm 3.06^{\mathrm{Aa}}$ & $186.44 \pm 1.04^{\mathrm{Aa}}$ & $151.62 \pm 5.21^{\mathrm{Ba}}$ & $149.87 \pm 1.71^{\mathrm{Ba}}$ & $149.24 \pm 3.43^{\mathrm{Ba}}$ \\
1 & $182.41 \pm 2.09^{\mathrm{Ab}}$ & $184.33 \pm 1.22^{\mathrm{Ab}}$ & $184.42 \pm 3.67^{\mathrm{Aa}}$ & $150.46 \pm 4.07^{\mathrm{Ba}}$ & $148.75 \pm 2.01^{\mathrm{Bab}}$ & $147.37 \pm 4.07^{\mathrm{Bbc}}$ \\
2 & $176.75 \pm 3.58^{\mathrm{Bc}}$ & $182.35 \pm 2.55^{\mathrm{Ab}}$ & $183.32 \pm 4.42^{\mathrm{Aa}}$ & $148.04 \pm 4.85^{\mathrm{Cab}}$ & $148.11 \pm 1.71^{\mathrm{Cb}}$ & $146.29 \pm 2.41^{\mathrm{Cc}}$ \\
6 & - & - & - & $143.94 \pm 3.67^{\mathrm{Ab}}$ & $141.39 \pm 1.26^{\mathrm{Ac}}$ & $141.88 \pm 3.73^{\mathrm{Ad}}$ \\
10 & - & - & - & $141.27 \pm 5.49^{\mathrm{Ab}}$ & $140.57 \pm 2.30^{\mathrm{Ac}}$ & $139.73 \pm 4.03^{\mathrm{Ad}}$ \\
\hline
\end{tabular}

Values are expressed as mean $\pm \mathrm{sd}$, and symbol - refers to unacceptable or spoilt samples. Means with different capital letters within the row are significantly different $(p<0.05)$. Means with different superscript lower case letters within the column are significantly different $(\mathrm{p}<0.05)$. 
increase in acidity might be prevented in pasteurized fruit-based juice (Nwachukwu and Ezeigbo, 2013).

The $0.1 \%$ of xanthan gum shows high acidity stability than $0.05 \%$ and control samples in both pasteurized and unpasteurized samples. Similarly, $\mathrm{pH}$ of pasteurized honey enriched with $0.1 \%$ of xanthan gum show insignificant different $(\mathrm{p}<0.05)$ from week 3 to week 10. These results were consistent with those reported by Juan and Shao (2016) that $\mathrm{pH}$ of apple juice with $0.2 \%$ of xanthan gum added was decreased slower than control samples that decreased stored at both $4^{\circ} \mathrm{C}$ and $25^{\circ} \mathrm{C}$. This might be due to a higher level of xanthan gum performs better rheological characteristics and helps to enhance the beverages $\mathrm{pH}$ and bioactive compound stability. Similarly as reported by Hussain et al. (2008) that the formation of weak acids resulted in increasing of acidity by oxidation of reducing sugars or by the breakdown of pectic substances and uronic acid. They stated that the problem can be prevented by adding novel stabilizer xanthan gum.

\subsection{Rheological behavior of honey beverages}

Most fluid foods do not have simple Newtonian rheological behavior, with their viscosities are independent of shear rate or shear stress (Maceiras et al., 2007). The presence of pectin and dispersed solid particles are responsible for the non-Newtonian behavior of purees (Dak et al., 2007). Table 3 shows that pasteurized honey beverages had greater apparent viscosity compared to unpasteurized honey beverages for $0 \%, 0.05 \%$ and $0.1 \%$ of xanthan gum concentration respectively. The result was similar to Espinosa et al. (2011), who reported that heat treatment at $105^{\circ} \mathrm{C}$ for 15 mins increase the viscosity by $2 \%$ of apple juice. According to Kumar et al. (2013), the increased viscosity of fruit-based juice might be due to the water loss during high-temperature processing. Heating process also promotes the degradation of cell walls resulting in the degradation and solubilization of pectin that results in an increase of viscosity of liquid phase (Espinosa et al., 2011)

The viscosity of both pasteurized and unpasteurized honey beverages increase with an increase of xanthan gum concentration. Pasteurized and unpasteurized 0.1\% xanthan gum honey beverages were higher than both pasteurized and unpasteurized $0.05 \%$ xanthan gum honey beverages.

\subsection{TPC of honey beverages}

The TPC in honey is strongly correlated with its antioxidant activity (Beretta et al., 2005) thus it can be used as a reliable parameter to indicate antioxidant activities in honey. From Table 4, it can be seen that the TPC of all pasteurized honey beverages) were significantly lower $(p<0.05)$ than unpasteurized honey beverages. This shows that TPC of all sample was reduced after pasteurized at $72^{\circ} \mathrm{C}$ for $15 \mathrm{~s}$ with control samples had decreased by $19.4 \%$, while TPC of $0.05 \%$ and $0.1 \%$ of xanthan gum honey beverages were decreased by $20.1 \%$ and $20 \%$ respectively during 10 weeks storage. This is believed due to thermal degradation and decomposition of phenolic compounds during heat treatment (Ranilla et al., 2010).

These results are consistent with Noriham et al. (2012) who shows that storage duration and pasteurization (at $84.5^{\circ} \mathrm{C}$ for $94 \mathrm{~s}$ ) were significantly affected the total phenolic contents in winter melon puree during six months of storage. Significant reductions occurred in a puree stored at room temperature $(41.01 \%)$, followed by frozen temperature (38.1\%) and chilling (33.27\%).

\subsection{Total plate count of honey beverages}

The microorganisms present in honey are fungus and yeast genera, such as Penicillium, Mucor,

Table 5. Total plate count of unpasteurized and pasteurized honey beverages during storage at $25 \pm 2{ }^{\circ} \mathrm{C}$.

\begin{tabular}{ccccccc}
\hline \multirow{2}{*}{$\begin{array}{c}\text { Shelf } \\
\text { life }\end{array}$} & \multicolumn{5}{c}{ Total plate count of honey beverages (CFU/ml) } \\
\cline { 2 - 7 }$($ week $)$ & \multicolumn{5}{c}{ Pasteurized } \\
\cline { 2 - 7 } & 0 & 0.05 & 0.1 & 0 & 0.05 & 0.1 \\
\hline 0 & $1.5 \pm 0.5^{\mathrm{Aa}}$ & $1.0 \pm 1.0^{\mathrm{Aa}}$ & $1.0 \pm 0.0^{\mathrm{Aa}}$ & $0.0 \pm 0.0^{\mathrm{Af}}$ & $0.0 \pm 0.0^{\mathrm{Ae}}$ & $0.0 \pm 0.0^{\mathrm{Ag}}$ \\
1 & - & - & - & $12.5 \pm 0.5^{\mathrm{Ae}}$ & $5.0 \pm 0.0^{\mathrm{Bd}}$ & $5.5 \pm 0.5^{\mathrm{Be}}$ \\
2 & - & - & - & $14.0 \pm 0.0^{\mathrm{Ad}}$ & $1.5 \pm 1.5^{\mathrm{Ce}}$ & $3.5 \pm 0.5^{\mathrm{Bf}}$ \\
3 & - & - & - & $16.0 \pm 1.0^{\mathrm{Ac}}$ & $4.5 \pm 0.5^{\mathrm{Bd}}$ & $4.0 \pm 1.0^{\mathrm{Bf}}$ \\
4 & - & - & - & $23.0 \pm 2.0^{\mathrm{Ab}}$ & $8.5 \pm 0.5^{\mathrm{Bc}}$ & $9.0 \pm 2.0^{\mathrm{Bd}}$ \\
6 & - & - & - & $52.0 \pm 3.0^{\mathrm{Aa}}$ & $20.0 \pm 3.0^{\mathrm{Bb}}$ & $17.0 \pm 2.0^{\mathrm{Bc}}$ \\
8 & - & - & - & $56.0 \pm 1.0^{\mathrm{Aa}}$ & $20.5 \pm 2.5^{\mathrm{Bb}}$ & $21.0 \pm 1.0^{\mathrm{Bb}}$ \\
10 & - & - & - & $56.5 \pm 5.5^{\mathrm{Aa}}$ & $26.5 \pm 1.5^{\mathrm{Ba}}$ & $26.0 \pm 0.0^{\mathrm{Ba}}$ \\
\hline
\end{tabular}

Values are expressed as mean $\pm \mathrm{sd}$, and symbol - refers to spoilt samples. Means with different capital letters within the row are significantly different $(\mathrm{p}<0.05)$. Means with different superscript lower case letters within the column are significantly different $(\mathrm{p}<0.05)$. 
Saccharomyces, Schizosaccharomyces and Torula (Ainul Hafiza et al., 2005). These microorganisms may cause fermentation of honey with high moisture content $(>21 \%)$. Table 5 shows that all unpasteurized honey started to spoil after the first week of storage with more than $50 \mathrm{CFU} / \mathrm{mL}$. According to the US Food and Drug Administration, total plate count should not exceed 50.0 $\mathrm{CFU} / \mathrm{mL}$ and $2.0 \mathrm{CFU} / \mathrm{mL}$ respectively, and coliform counts should be nil in $100 \mathrm{~mL}$ beverage sample. These results were similar to De Roeck et al. (2009) who reported that control samples (unpasteurized mango juice) were spoilt during the first week of storage at ambient temperature $30 \pm 2^{\circ} \mathrm{C}$. This might be due to the presence of enzymes such as pectinase and vegetative microorganisms including bacteria, molds and yeasts in unpasteurized samples that could ferment and cause spoilage (Akpeji et al., 2017).

For pasteurized honey beverages, colony form units $(\mathrm{CFU} / \mathrm{mL})$ in $0.05 \%$ and $0.1 \%$ of xanthan gum enriched honey beverages were significantly lower in the count $(p<0.05)$ and increased slower than pasteurized control sample ( $0 \%$ xanthan gum) after 10 weeks of storage. This is possible due to pseudoplasticity of xanthan gum that helps improve suspension and emulsification. This also indicates that xanthan gum is good at holding particles in suspension (Sworn, 2009), thus it may help in preventing microorganisms from consuming stabilized sugars such as glucose and fructose in honey beverages.

\section{Conclusion}

In this study, there was significantly decreased in $\mathrm{pH}$, TSS, total phenolic compound, colony form units $(\mathrm{CFU} / \mathrm{mL})$, with the significant increase in the viscosity of xanthan gum enriched honey beverages after pasteurization at $72^{\circ} \mathrm{C}$ for $15 \mathrm{~s}$. Xanthan gum enriched honey beverages exhibited pseudoplastic or shear thinning behavior and insignificant increase in apparent viscosity was observed after pasteurization. Unpasteurized honey beverages were spoilt during the first week of storage at $25 \pm 2^{\circ} \mathrm{C}$ and fermented smell with a significant decline in total soluble solids and $\mathrm{pH}$. For xanthan gum enriched pasteurized honey beverages, all samples remain acceptable during 10 weeks of storage at $25 \pm 2^{\circ} \mathrm{C}$. On the other hand, total soluble solids, $\mathrm{pH}$, total phenolic compound and total plate count of xanthan gum enriched honey beverages show significantly higher stability than in the control sample. The honey beverage containing $0.1 \%$ of xanthan gum show significantly higher $(\mathrm{p}<0.05)$ stability in total soluble solids and total plate count than honey beverages containing $0.05 \%$ xanthan gum.

\section{Acknowledgement}

The authors would like to express their gratitude to Universiti Putra Malaysia for technical support.

\section{References}

Ainul Hafiza, A.H., Yusof, N. and Maimon, A. (2005). Potential of Malaysian Local Honey as an Antibacterial Agent. Sains Malaysiana, 34(1), 17-20

Akpeji, S.C., Adebayo-Tayo, B.C., Sanusi, J.F. and Alao, S.O. (2017). Production and properties of probiotic soursop juice using Pediococcus pentosaceus LBF2 as starter. International Journal of Biochemistry Research and Review 17(2), 1-10. https://doi.org/10.9734/IJBCRR/2017/32954

Alvarez, E., Cancela, M.A. and Maceiras, R. (2006). Effect of temperature on rheological properties of different juices. International Journal of Food Properties, $\quad 9, \quad$ 135-146. https:// doi.org/10.1080/10942910500473996

Beretta, G., Granata, P., Ferrero, M., Orioli, M. and Facino, R.M. (2005). Standardization of antioxidant properties of honey by a combination of spectrophotometric/fluorimetric assays and chemometrics. Analytica Chimica Acta, 533, 185191. https://doi.org/10.1016/j.aca.2004.11.010

Brian, K. (2015). A school-based intervention for diabetes risk reduction. New England Journal of Medicine, 36(3), 443-453

Bull, M.K., Zerdin, K., Howe, E., Goicoechea, D., Paramanandhan, P., Stockman, R., Sellahewa, J., Szabo, E.A., Johnson, R.1. and Stewart, C.M. (2004). The effect of high-pressure processing on the microbial, physical and chemical properties of Valencia and Navel orange juice. Innovative Food Science and Emerging Technologies, 5, 135-149. https://doi.org/10.1016/j.ifset.2003.11.005

Castro, M.P., Rojas, A.M., Campos, C.A. and Gerschenson, L.N. (2009). Effect of preservatives, tween 20, oil content and emulsion structure on the survival of Lactobacillus fructivorans in model salad dressings. LWT - Food Science and Technology, 42 (8), 1428-1434. https://doi.org/10.1016/ j.lwt.2009.02.021

Chaikham, P. and Apichartsrangkoon, A. (2012). Comparison of dynamic viscoelastic and physiochemical properties of pressurised and pasteurized longan juice with xanthan addition. Food Chemistry, 134(4), 2194-2200. https:// doi.org/10.1016/j.lwt.2009.02.021

Chia, S.L., Rosnah, S., Noranizan, M.A. and Wan, Ramli W.D. (2012). The effect of storage on the quality 
attributes of ultraviolet-irradiated and thermally pasteurised pineapple juices. International Food Research Journal, 19(3), 1001-1010

Codex Alimentarius Commission (2013). Revised codex standard for honey. Codex STAN 12-1981. USA: Codex Alimentarius FAO-WHO

Dak, M., Verma, R.C. and Jaaffrey, S.N.A. (2007). Effect of temperature and concentration on rheological properties of "Kesar" mango juice. Journal of Food Engineering, 80(4), 1011-1015. https://doi.org/10.1016/j.jfoodeng.2006.08.011

De Roeck, A., Mols, J., Sila, D.N., Duvetter, T., Van, Loey, A. and Hendrickx, M. (2010). Improving the hardness of thermally processed carrots by selective pretreatments. Food Research International, 43(5), 129-1303. https://doi.org/10.1016/ j.foodres.2010.03.011

Doner, L.W. (2006). The sugars of honey. Journal of Science of Food and Agriculture, 28(5), 443-456. https://doi.org/10.1002/jsfa.2740280508

Drewnowski, A., Monsivais, P., Maillot, M. and Darmon, N. (2007). Low energy-density diets are associated with higher diet quality and higher diet costs in French adults. Journal of the American Dietetic Association, 107(6), 1028-1032. https:// doi.org/10.1016/j.jada.2007.03.013

Espinosa, L., To, N., Symoneaux, R., Renard, C.M.G.C., Biau, N. and Cuvelier, G. (2011). Effect of processing on rheological, structural and sensory properties of apple puree. Procedia Food Science, 1, 513-520.

https://doi.org/10.1016/ j.profoo.2011.09.078

Gabriel, A.A. and Nakano, H. (2009). Inactivation of Salmonella, E. coli and Listeria monocytogenes in phosphate-buffered saline and apple juice by ultraviolet and heat treatments. Food Control, 20, 443-446.

j.foodcont.2008.08.008

Habib, H.M., Al Meqbali, F.T., Kamal, H., Souka, U.D. and Ibrahim, W.H. (2014). Bioactive components, antioxidant and DNA damage inhibitory activities of honeys from arid regions. Food Chemistry, 153, 2834. https://doi.org/10.1016/j.foodchem.2013.12.044

Huber, A.K. (2016). Satisfaction, repurchase intent, and repurchase behavior: Investigating the moderating effect of customer characteristics. Journal of International Marketing, 31(1), 131-142.

Hussain, I., Zeb, A., Shakir, I. and Shah, A.S. (2008). Combined effect of potassium sorbate and sodium benzoate on individual and blended juice of apricot and apple fruit grown in Azad Jammu and Kashmir. Pakistan Journal of Nutrition, 7(1), 181-185. https:// doi.org/10.3923/pjn.2008.181.185

Juan, M.L. and Shao, P.N. (2016). The functional and nutritional aspects of hydrocolloids in foods. Food Hydrocolloid, 53(1), 46-61.

Kumar, Bawa, R., Kathiravan, A.S. and Nadanasabapapathi, S. (2013). Thermal processing of mango nectar (Mangifera indica) and its effect on chemical, microbiological and sensory quality characteristics. International Journal of Advanced Research 1(8), 261-273.

Maceiras, R, Alvarez, E. and Feng, H. (2007). Efficacy of sodium chloriteasan inhibitor enzymatic browning. Journal of Agriculture and Food Chemistry, 55, 5312-5319.

Noriham, A., Wan Saidatul Syida, W.K., Zainal, S., Nurain, A. and Khairusy, S.Z. (2012). Optimization of thermal processing condition for winter melon puree using response surface methodology. 2012 IEEE Colloquium on Humanities, Science and Engineering (CHUSER), 3-4 December 2012. Retrieved from IEEE Xplore website: https:/ ieeexplore.ieee.org/document/6504416

Nwachukwu, E. and Ezeigbo, C.G. (2013). Changes in the microbial, population of pasteurized soursop juice treated with benzoate and lime during storage. African Journal of Microbiology Research, 7(31), 3992-3995.

Oliveira, R.P.D.S., Torres, B.R., Perego, P., Oliveira, M.N.D. and Converti, A. (2012). Co-metabolic models of Streptococcus thermophilus in co-culture with Lactobacillus bulgaricus or Lactobacillus acidophilus. Biochemical Engineering Journal, 62, 62-69.

Peter, A. and Aylor, D.E. (2009). Settling spend of corn (Zea mays) pollen. Journal of Aerosol Science, 33 (11), 1601-1607. https://doi.org/10.1016/ j.bej.2012.01.004

Queiroz, C., Moreira, C.F.F., Lavinas, F.C, Lopes, M.L.M, Fialho, E. and Valente-Mesquita, V.L. (2010). Effect of high hydrostatic pressure on phenolic compounds, ascorbic acid and antioxidant activity in cashew apple juice. High Pressure Research, 30(4), 507-513. https:// doi.org/10.1080/08957959.2010.530598

Ranilla, L.G., Kwon, Y.I., Genovese, M.I., Lajolo, F.M. and Shetty, L. (2010). Effect of thermal treatment on phenolic compounds and functionality linked to type 2 diabetes and hypertension management system of Peruvian and Brazilian bean culticars (Phaseolus vulgaris L.) using in vitro methods. Journal of Food Biochemistry, 34(2), 329-355. https:// doi.org/10.1111/j.1745-4514.2009.00281.x 
Rivas, A., Rodrigo, D., Martinez, A., Barbosa-Canovas, G.V. and Rodgrigo, M. (2006). Effect of PEF and heat pasteurization on the physical-chemical characteristics of blended orange and carrot juice. Food Science and Technology, 39, 1163-1170.

Rosen, J. and Gothard, L.Q. (2010). Encyclopedia of physical science. Vol. 1. New York: Infobase Publishing.

Rungnaphar, P., Natee, Y. and Thongchai, S. (2011). Effect of xanthan gum on the quality of syrup thickened by modified starch during heating and storage. Kasetsart Journal (Natural Science), 45, 128-135.

Sanchez-Moreno, C., Plaza, L., De Ancos, B. and Cano, M.P. (2006). Nutritional characterization of commercial traditional pasteurized tomato juices: Carotenoids, vitamin $\mathrm{C}$ and radical scavenging capacity. Food Chemistry, 98, 749-756. https:// doi.org/10.1016/j.foodchem.2005.07.015

Silva, F.M. and Gibbs, P. (2004). Target selection in designing pasteurization process for shelf-stable high acid fruit products. Critical Reviews in Food Science and Nutrition, 44, 353-360. https:// doi.org/10.1080/10408690490489251

Sworn, G. (2009). Xanthan Gum. In Imeson A. (Ed.). Food Stabilisers, Thickeners and Gelling Agents. Oxford, United Kingdom: Wiley-Blackwell. https:// doi.org/10.1002/9781444314724.ch17

Tome, K., Kesic, A., Mazalovic, M., Catovic, B. and Crnikic, A. (2008). The influence of temperature and daylight effect on contents L-ascorbic acid in honey from Bosnia and Herzegovina. Journal of Engineering, 2, 1584-1665.

US FDA (2002). Maximum use of xanthan gum purified by recovery with ethanol in the Food Categories Listed by the US FDA. Retrieved on February 14, 2017 from FDA website: http:/www. fda.gov/ downloads/food/ingredientspackaginglabeling/ GRAS/noticeinventory/UCM261607

Xiang, B., Sundararajan, S., Solval, K.M., EspinozaRodezno, L., Aryana, K. and Sathivel, S. (2014). Effects of pulsed electric fields on physicochemical properties and microbial inactivation of carrot juice. Journal of Food Processing and Preservation, 38, 1556-1564. https://doi.org/10.1111/jfpp.12115 